small tube. In addition the electrical insulation is more permanent and the lag smaller.

WashingtoN, D. C.

[Contributions from the Research laboratory of Physical Chemistry of the MassachuseTts InstituTe OF TechNOLOGY.-NO. 134.]

\title{
THE DISSOCIATION PRESSURES OF IRON NITRIDES.
}

By ARThur A. NOYes and Leighton B. SMIth.

Received December 6, 1920.

I. Introduction.

In the synthesis of ammonia from its elements on an industrial scale catalysts consisting of iron in association with other metals, especially molybdenum, have been found to be especially satisfactory. In view of the extensive empirical investigations that have been made on such catalysts, there would seem to be little hope of largely increasing their effectiveness except through theoretical knowledge of the mechanism of their action; and one of the main factors in this mechanism is probably the extent to which the nitrogen and hydrogen gases are absorbed by or combined with the metals of the catalyst. The combination of nitrogen with the iron to form a nitride, and the tendency of the latter to form solid solutions with the iron itself, seem especially worthy of further investigation; and as a contribution in that direction this research was undertaken with the view of determining the dissociation pressures of iron nitrides under different conditions.

\section{Principle of the Method.}

Several investigators have attempted to prepare an iron nitride directly from its elements and to estimate its dissociation pressure. Baur and Voorman ${ }^{1}$ worked with pressures of nitrogen up to 14 atmospheres, while Maxted $^{2}$ went to 200 atmospheres without any indication that the dissociation pressure was being approached. Groebe ${ }^{3}$ states, to be sure, that nitrogen is taken up to an extent of $0.25 \%$ by finely divided iron at $450-850^{\circ}$. It is, however, well $\mathrm{known}^{4}$ that an iron nitride is readily prepared by the action of ammonia gas on iron, rapidly at $460^{\circ}$, in accordance with the equation, $4 \mathrm{Fe}+2 \mathrm{NH}_{3}=2 \mathrm{Fe}_{2} \mathrm{~N}+3 \mathrm{H}_{2}$.

The study of this ammonia reaction seemed to offer the most promising method of throwing more light on the iron nitrides and to furnish an indirect means of determining their dissociation pressures. This study was therefore undertaken. The principle of the method will be first described.

${ }^{1}$ Baur and Voorman, $Z$, physik. Chem., 52, 467 (1905).

2 Maxted, J. Soc. Chem. Ind., 37, 105 (1918).

${ }^{3}$ Groebe, $Z$. angew. Chem., 27,334 (1914).

${ }^{4}$ See Fowler, J. Chem. Soc. (London), 79, 285 (1901); and White and Kirschbaum, This Journal, 28, 1343 (1906). 
The decomposition of any solid nitride $\mathrm{Fe}_{x} \mathrm{~N}$ may be expressed by the following general equation,

$$
2 \mathrm{Fe}_{x} \mathrm{~N}+3 \mathrm{H}_{2}=2 x \mathrm{Fe}+2 \mathrm{NH}_{3} .
$$

This reaction is, however, bound to be attended to a greater or less extent by the 2 reactions expressed by the following equations.

$$
\mathrm{N}_{2}+3 \mathrm{H}_{2}=2 \mathrm{NH}_{3} \text { (II); and } 2 \mathrm{Fe}_{x} \mathrm{~N}=2 x \mathrm{Fe}+\mathrm{N}_{2} \text {. }
$$

The equilibrium conditions of these 3 reactions at any definite temperature are expressed by the equations,

$$
K_{1}=\frac{\left(p_{\mathrm{NH}_{3}}\right)^{2}}{\left(p_{\mathrm{H}_{2}}\right)^{3}} \quad(1) ; \quad K_{2}=\frac{\left(p_{\mathrm{NH}_{8}}\right)^{2}}{p_{\mathrm{N}_{2}}\left(p_{\mathrm{H}_{3}}\right)^{3}} \quad(2) ; \quad p_{\mathrm{N}_{2}}^{\prime}=f \text { (s.ph.) }
$$

In the last equation $f$ (s.ph.) denotes a function of the composition and character of the solid phase.

Assuming these reactions all came to equilibrium (in which case $p_{\mathrm{N}_{2}}=$ $\left.p^{\prime} \mathrm{N}_{2}\right)$, we get by combination,

$$
p_{\mathrm{N}_{2}}^{\prime}=K_{1} / K_{2} \text {. }
$$

That is, the dissociation-pressure of the iron nitrides is equal to the ratio of the equilibrium constants of Reactions I and II. Since the equilibrium constant of Reaction II (the formation of ammonia out of its elements) is known, the determination, contemplated in this research, of the equilibrium constant of Reaction I would make possible a computation of the dissociation-pressure of the ritride.

The success of this determination will evidently depend on the possibility of finding conditions under which (1) the dissociation of ammonia takes place so much more slowly than the establishment of the equilibrium of the iron nitride reaction as not seriously to displace this equilibrium; and (2) the temperature is high enough and consequently the equilibrium constant of the ammonia synthesis small enough to make the equilibrium pressure of the ammonia so small that it can be handled and measured. It is to be noted that this equilibrium pressure is the pressure of ammonia that (with the prevailing pressure of hydrogen) would be in equilibrium with nitrogen at a pressure equal to the (doubtless very large) dissociation pressure of the iron nitride. In other words, it is the pressure which the ammonia must have in order that it may be potentially able to produce by dissociation a nitrogen pressure just sufficient to prevent decomposition of the iron nitride. Thus, even though the dissociation pressure of the nitride be thousands of atmospheres, the pressure of ammonia at which the nitride reaction (Reaction I) is in equilibrium when the hydrogen pressure is say one atmosphere might be not far from one atmosphere provided the temperature be so high that all but a few hundredths of one per cent. of the ammonia would be dissociated into its elements in case time were allowed for this dissociation to take place. 
Fortunately, it was found that the nitride-formation reaction proceeds rapidly enough to make it possible to determine its equilibrium conditions approximately in spite of the disturbing reactions; and the problem consisted in allowing the gases to remain in contact with the solid phase long enough to establish this equilibrium and in removing and cooling them before the slower, disturbing reactions caused serious complications. It was also of great importance to approach the equilibrium from both sides; and this was in fact accomplished.

The dissociation pressure of iron nitride and the equilibrium conditions of the nitride formation reaction, in case a solid solution of the nitride in iron is formed, will depend on the composition of that solution. The composition of the solid phase was therefore varied over a wide range; and measurements of the equilibria were made in an attempt to secure results which might be interpreted in relation to the composition of that phase.

\section{The Experimental Method.}

In brief, the method consisted in admitting ammonia or hydrogen to the reaction tube containing the iron and iron nitride, and after a certain period suddenly withdrawing and cooling a quantity of the gas and analyzing it. Two pairs of such experiments were made, and then the furnace was rapidly cooled and samples of the nitride withdrawn and analyzed. Each pair of experiments consisted of one experiment from the ammonia and one from the hydrogen side.

The apparatus is represented in the figure. The nitride was contained in the hardglass bomb tube in the furnace $\mathrm{J}$. The bomb contained such a large quantity of nitride that the composition of the solid never changed more than 0.1 or $0.2 \%$ during the 2 pairs of experiments. This tube was connected by a fine capillary to a stopcock which communicated with the Toepler Pump M or the gas Reservoir I. The pump served to evacuate the apparatus and to remove samples of gas. In the mercury Buret $\mathrm{N}$ the total volume of the gas sample was measured. The ammonia was then absorbed in sulfuric acid at $P$, and the remaining hydrogen and nitrogen were measured over water in the buret $R$. The gases were next transferred to the explosion Pipet $S$, where oxygen was added and the mixture exploded. The residual gases were again measured in the buret $\mathrm{R}$, corrections for the vapor pressure of water being applied.

Commercial liquid ammonia was stored in a small steel cylinder (shown at the upper right-hand corner of the figure). The ammonia gas, after passing the trap $B$, was freed from oxygen by passage through alkaline pyrogallol in the washer at $\mathrm{C}$. Moisture was removed by soda lime in the tube $D$. An automatic blow-off valve was introduced at $A$, to avoid excess of pressure.

Hydrogen was prepared by the electrolysis of a sodium hydroxide solution in the water-cooled Generator E. The gas was then freed from oxygen by alkaline pyrogallol in $F$ and dried with sulfuric acid in the wash-bottle $G$. An automatic pressure blowciff valve at $\mathrm{H}$ was provided.

The furnace indicted in section at $\mathrm{J}$ was provided with two auxiliary end heaters $a$ and $b$, which made possible uniform heating of the bomb tube. The temperature was rneasured with a triple junction copper-advance thermocouple, used in conjunction with a Leeds and Northrup portable potentiometer. 
The low pressures obtained in evacuating the bomb tube were measured with the barometer Gage $\mathrm{L}$, and the reaction pressures were measured with the short open manometer $\mathrm{K}$.

The iron nitrides used in the reaction bulb were made as follows. Pure iron was prepared by the reduction of ferric oxalate flakes by hydrogen. Samples of this iron were then converted to a greater or less extent into nitride by treatment with ammonia at $460^{\circ}$. In carrying out this conversion, the iron was placed in a large Pyrex glass

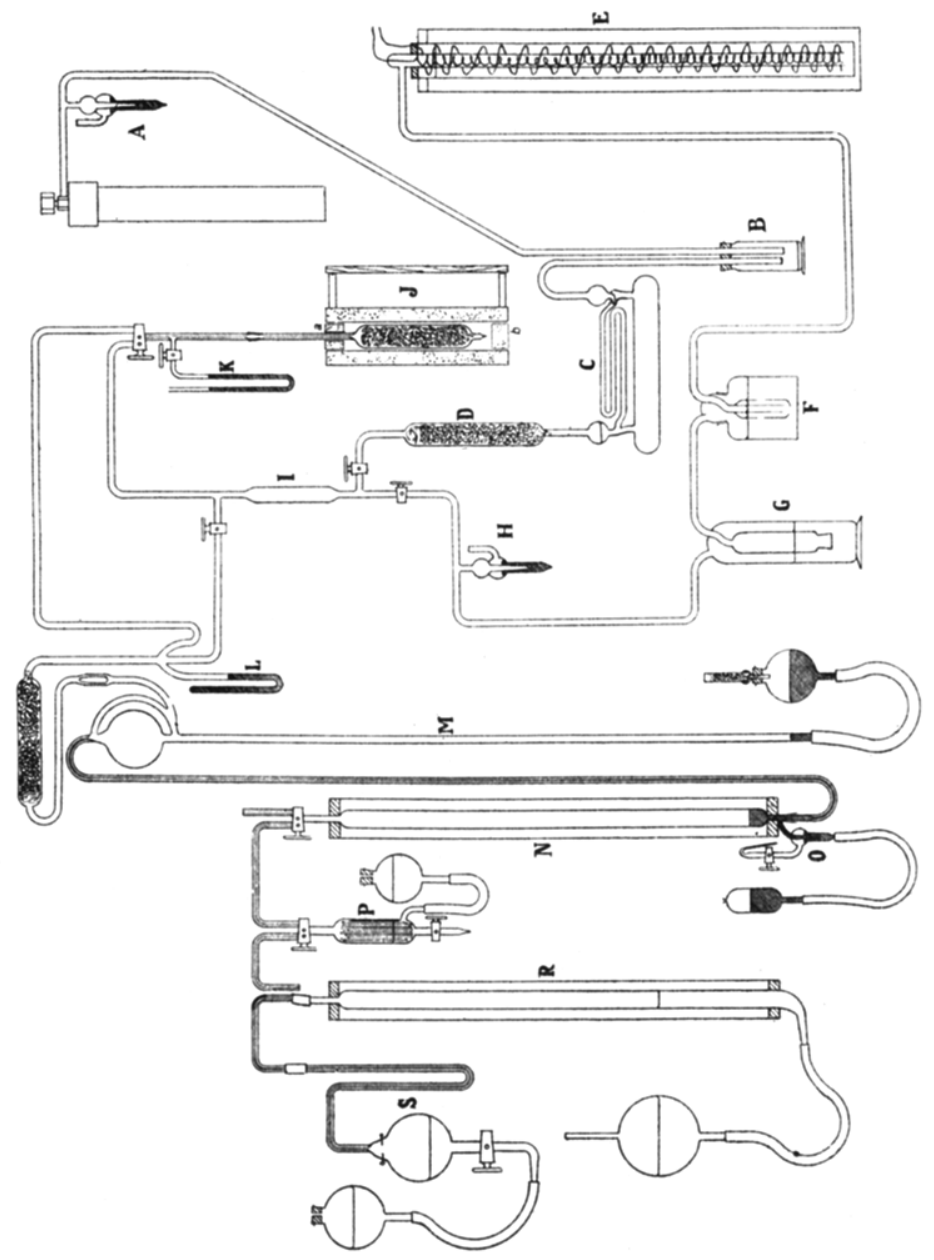

tube, and the ammonia was introduced through a concentric perforated tube within the larger tube. Exit for the gases was provided at both ends of the larger tube. This method gave very homogeneous samples.

In removing samples for analysis air had to be carefully excluded, since the iron and the nitrides of low nitrogen percentage were pyrophoric. Small light tubes were attached to the lower end of the reaction tube, and nitrogen swept through. The exit-end of the sample tube was then sealed, and nitride allowed to drop into it. The sample 
tube could then be sealed off and weighed. The composition of the nitride was determined by rapid reduction with hydrogen and absorption of the ammonia in sulfuric acid. The tip of the sample tube was broken off within the reduction tube, while a stream of hydrogen was passing.

\section{The Experimental Data and the Equilibrium Constants of the Reaction.}

The results of the experimental work are shown in Table I. The perfect-gas law was used in calculating the mol fractions of the gases; for up to one atmosphere the molecular volume of ammonia, hydrogen, and nitrogen differ from that of a perfect gas by less than $0.2 \%$. The temperature was always $460^{\circ} \pm 3$ to $5^{\circ}$. The composition of the solid phase is shown by the atomic ratio Fe: $\mathrm{N}$ given in the last column. The molal percentage of nitrogen shows the extent to which the ammonia and the iron nitride decomposed in the 10-30 minutes during which the equilibrium was being established.

Table I.-Composition of the Gas Mixtures and the Corresponding EquilibRIUM-CONSTANTS.

\begin{tabular}{|c|c|c|c|c|c|c|c|c|c|}
\hline \multirow[b]{2}{*}{ Fixpt. } & \multirow[b]{2}{*}{$\begin{array}{l}\text { Gas at } \\
\text { start. }\end{array}$} & \multirow[b]{2}{*}{$\begin{array}{l}\text { Press. } \\
\text { in atm. }\end{array}$} & \multirow[b]{2}{*}{$\begin{array}{l}\text { Contact } \\
\text { in min. }\end{array}$} & \multicolumn{3}{|c|}{ Molal percentage of. } & \multicolumn{2}{|c|}{$K_{1}=\left(p \mathrm{NH}_{3}\right)^{2} /\left(p \mathrm{H}_{2}\right)^{3}$} & \multirow[b]{2}{*}{$\begin{array}{l}\text { Ratio } \\
\text { Fe:N. }\end{array}$} \\
\hline & & & & $\frac{\mathrm{MO}_{0}}{\mathrm{NH}_{3}}$ & perced & $\mathrm{N}_{2}$ & $\begin{array}{c}\text { Separate } \\
\text { values. }\end{array}$ & $\begin{array}{c}\text { Best } \\
\text { values. }\end{array}$ & \\
\hline $1 \ldots$ & $\mathrm{NH}_{3}$ & 1.043 & 20 & 9.7 & 28.5 & 61.8 & 0.39 & & 17.1 \\
\hline 2. & $\mathrm{H}_{2}$ & 1.011 & 20 & 36.9 & 52.3 & 10.9 & 0.94 & 1.0 & 17.1 \\
\hline $3 \ldots$ & $\mathrm{NH}_{3}$ & 1.008 & 20 & 26.8 & 32.5 & 40.7 & 2.08 & & 17.1 \\
\hline $4 \ldots$ & $\mathrm{H}_{2}$ & 1.021 & 20 & 59.9 & 32.6 & 7.5 & 10.14 & (?) & 12.4 \\
\hline $5 \ldots$. & $\mathrm{H}_{2}$ & 1.039 & 30 & 49.9 & 40.3 & 9.7 & 3.66 & & 12.4 \\
\hline $6 \ldots$ & $\mathrm{NH}_{3}$ & 1.034 & 20 & 21.3 & 30.8 & 47.9 & 1.50 & & $9 . \overline{3}$ \\
\hline $7 .$. & $\mathrm{H}_{2}$ & 1.018 & 20 & 30.2 & 60.2 & 9.8 & 0.41 & 0.8 & 9.5 \\
\hline 8. & $\mathrm{H}_{2}$ & 1.020 & 20 & 31.3 & 62.5 & 6.3 & 0.39 & & 9.5 \\
\hline $9 \ldots$ & $\mathrm{NH}_{3}$ & 1.033 & 20 & 22.9 & 39.3 & 37.8 & 0.84 & & 9.5 \\
\hline $10 \ldots$ & $\mathrm{NH}_{3}$ & 1.017 & 20 & 38.3 & 40.6 & 21.1 & 2.16 & . & 9.0 \\
\hline $11 \ldots$ & $\mathrm{H}_{2}$ & 1.026 & 20 & 39.8 & 56.0 & 4.2 & 0.88 & 1.2 & 9.0 \\
\hline $12 \ldots$ & $\mathrm{H}_{2}$ & 1.026 & 20 & 35.8 & 58.7 & 5.5 & 0.62 & & 9.0 \\
\hline $13 \ldots$ & $\mathrm{NH}_{3}$ & 1.040 & 20 & 39.3 & 48.6 & 12.1 & 1.29 & & 9.0 \\
\hline $14 \ldots$ & $\mathrm{NH}_{3}$ & 1.021 & 20 & 55.5 & 40.5 & 4.0 & 4.54 & & 7.72 \\
\hline $15 \ldots$ & $\mathrm{NH}_{3}$ & 1.008 & 15 & 60.6 & 36.7 & 2.7 & 7.37 & 5.2 & 7.72 \\
\hline $16 \ldots$ & $\mathrm{H}_{2}$ & 1.000 & 15 & 38.1 & 32.1 & 29.8 & 4.39 & & 7.72 \\
\hline $17 \ldots$ & $\mathrm{H}_{2}$ & 1.006 & 10 & 68.9 & 25.4 & 5.7 & 28.8 & & 4.87 \\
\hline $18 \ldots$ & $\mathrm{NH}_{\mathrm{i}}$ & 1.018 & 10 & 70.3 & 24.2 & 5.5 & 34.8 & & 4.87 \\
\hline $19 \ldots$ & $\mathrm{H}_{2}$ & 1.037 & 30 & 69.5 & 25.5 & 5.0 & 28.1 & 30 & 4.87 \\
\hline $20 \ldots \ldots$ & $\mathrm{NH}_{3}$ & 1.032 & 30 & 65.9 & 24.6 & 9.5 & 28.3 & & 4.87 \\
\hline 21. & $\mathrm{NH}_{3}$ & 1.019 & 15 & 55.3 & 43.7 & 1.0 & 3.59 & & 2.59 \\
\hline $22 \ldots$ & $\mathrm{H}_{2}$ & 1.007 & 15 & 38.8 & 60.5 & 0.7 & 0.68 & 2.1 & 2.59 \\
\hline $23 \ldots$ & $\mathrm{H}_{2}$ & 1.016 & 15 & 34.9 & 65.3 & 0.8 & 0.45 & & 2.59 \\
\hline $24 \ldots \ldots$ & $\mathrm{NH}_{3}$ & 1.041 & 15 & 53.4 & 42.5 & 4.1 & 3.57 & & 2.59 \\
\hline
\end{tabular}




\section{Discussion of the Results.}

It will be noted that, although the separate experiments with any definite solid phase give rather discordant values of the equilibrium constant, yet the values where the equilibrium was approached from the ammonia side are (except in the first 2 sets of experiments) larger than those where it was approached from the hydrogen side, thus making it certain that the true value lies between these 2 observed values.

It will be seen that the equilibrium-constants remain substantially constant, with values between 0.8 and 1.2 (best value 1.0 ), as long as the atomic ratio of $\mathrm{N}: \mathrm{Fe}$ is not greater than $1 / 9$. This indicates that throughout this interval of composition solid solutions are not formed, but that a definite nitride, perhaps $\mathrm{Fe}_{8} \mathrm{~N}$, is being produced as a separate solid phase. In the interval of composition between about $\mathrm{N}: \mathrm{Fe}=1 / 8$ and $\mathrm{N}: \mathrm{Fe}=1 / 5$, the values of the equilibrium constant are much larger, increasing from 1.0 to 5.2 for $\mathrm{N}: \mathrm{Fe}=1: 7.7$, and to 30 for $\mathrm{N}: \mathrm{Fe}=1: 4.9$. This may be due either to the formation of solid solutions of a new metastable nitride, such as $\mathrm{Fe}_{4} \mathrm{~N}$, in the nitride first formed, or to the formation of 2 metastable nitrides, such as $\mathrm{Fe}_{6} \mathrm{~N}$ and $\mathrm{Fe}_{4} \mathrm{~N}$, as separate solid phases. Finally, when the ratio $\mathrm{N}: \mathrm{Fe}$ becomes $1: 2.6$, the equilibrium-constant falls to 2.1 , indicating the formation of a relatively stable nitrice, probably the well-known $\mathrm{Fe}_{2} \mathrm{~N}$, which may be present together with the original nitride $\left(\mathrm{Fe}_{8} \mathrm{~N}\right.$ ?) or the metastable one $\left(\mathrm{Fe}_{4} \mathrm{~N}\right.$ ?).

\section{The Dissociation-Pressures of the Nitrides.}

From each of the 4 best values of the equilibrium-constant $K_{1}$ considered in the preceding section, the dissociation-pressure $p_{\mathrm{N}_{2}}$ of the nitrides present in the solid phase may be calculated with the aid of Equation 4 derived in the second section of this article. This equation is $p_{\mathrm{N}_{2}}=K_{1} / K_{2}$ where $K_{2}$ denotes the equilibrium-constant of the reaction $\mathrm{N}_{2}+3 \mathrm{H}_{2}=$ $2 \mathrm{NH}_{3}$. The value of the constant $K_{2}$ can best be derived from the freeenergy equation computed by Lewis and Adams ${ }^{1}$ on the basis of the existing equilibrium data. For the free-energy decrease $-\Delta F$ in calories attending the change in state $\mathrm{N}_{2}$ (one atm.) $+3 \mathrm{H}_{2}$ (one atm.) $=2 \mathrm{NH}_{3}$ (one atm.), they find:

$$
-\Delta F=21,400-11.0 T \ln T+0.00235 T^{2}+22.0 T .
$$

This is to be combined with the general thermodynamic relation

$$
-\Delta F=R T \ln K_{2} \text {. }
$$

Making this combination and introducing for $T$ the value $460+273.1$, we find for $K_{2}$ at this temperature the value $5.10 \times 10^{-5}$.

The values of the dissociation-pressure at $460^{\circ}$ in atmospheres corresponding to the equilibrium-constant $K_{1}$ are then found to be those given in Table II.

1 This Journal, 37, 2309 (1915). 
TABle II.-Dissociation-Pressure at $460^{\circ}$ OF the Nitrides Present in Solid Phases of Various Compositions.

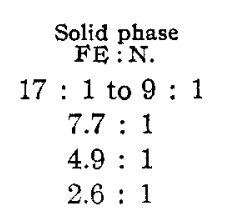

\begin{tabular}{|c|}
\hline $\begin{array}{l}\text { Equilibrium } \\
\text { constant } \mathrm{K}_{1} \text {. }\end{array}$ \\
\hline 1.0 \\
\hline 5.2 \\
\hline 30.0 \\
\hline 2.1 \\
\hline
\end{tabular}

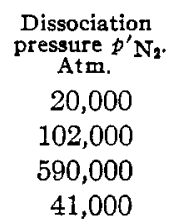

\section{Summary.}

A method has been described for determining the equilibrium conditions of the reaction between iron, ammonia, solid iron nitrides, and hydrogen; and the results of 24 experiments at $460^{\circ}$ have been presented. The equilibrium-constant given by the expression $\left(p_{\mathrm{NH}_{3}}\right)^{2} /\left(p_{\mathrm{H}_{2}}\right)^{3}$, was found to vary with the proportion of nitrogen present in the solid phase. Thus with increasing nitrogen constant this expression remained constant at the value 1.0 till the atomic ratio $\mathrm{N}: \mathrm{Fe}$ became $1: 9$; later increased rapidly, namely, to 5.2 for $\mathrm{N}: \mathrm{Fe}=1: 7.7$ and to 30 , for $\mathrm{N}: \mathrm{Fe}=1: 4.9$; and finally assumed the much smaller value 2.1 for $\mathrm{N}: \mathrm{Fe}=1: 2.6$. These results indicate the formation: first, of a nitride of small nitrogencontent, perhaps $\mathrm{Fe}_{8} \mathrm{~N}$; then, either of a metastable nitride, such as $\mathrm{Fe}_{4} \mathrm{~N}$, in solid solution with the first one, or of two separate metastable nitrides, such as $\mathrm{Fe}_{6} \mathrm{~N}$ and $\mathrm{Fe}_{4} \mathrm{~N}$, as separate solid phases; and finally, of a stable nitride, probably the well-known $\mathrm{Fe}_{2} \mathrm{~N}$.

By combining this equilibrium constant with the constant $\left(\mathrm{p}_{\mathrm{NH}_{8}}\right)^{2}$ / $p_{\mathrm{N}_{2}}\left(p_{\mathrm{H}_{2}}\right)^{3}$ for the formation of ammonia, the dissociation-pressure $p_{\mathrm{N}_{2}}$ of the nitrides in these various solid phases were computed and found to be 20,$000 ; 102,000 ; 590,000$; and 41,000 atmospheres, respectively.

The work affords a striking example of a metastable chemical equilibrium and illustrates the possibility of determining through the study of such equilibria the equilibrium conditions of reactions not directly accessible to measurement. Thus, in this case, it was possible to determine approximately the equilibrium constant of the iron ammonia reaction at a pressure of about one atmosphere under conditions where, if complete equilibrium were established, all but about $0.1 \%$ of the ammonia would be dissociated, and where the iron nitride, with its dissociation pressure of at least 20,000 atmospheres, would not form at all. 